\title{
At-home cancer screening: a solution for China and other developing countries with a large population and limited number of healthcare practitioners
}

\author{
Chao-Nan Qian *
}

\begin{abstract}
Five-year survival rate for patients with all cancers combined, in China, is only $30.9 \%$, which is much lower than those in developed countries. The three main reasons for the low cancer curative rates in China include differences in the spectrum of cancer types, in early detection rates, and in the percentage of cancer patients receiving standardized treatment between China and developed countries. The most important mechanism for improving the curative rate is to improve early detection rates of major cancers in China using novel and affordable technologies that can be operated at home by the patients themselves. This attempt could be helpful in setting up a practical example for other developing countries with limited medical resources and a limited number of healthcare practitioners.
\end{abstract}

Keywords: The spectrum of cancer types, At-home cancer screening, Early detection rate, Standardized treatment, Lung cancer, Cervical cancer, Gastric cancer, Colorectal cancer, Breast cancer, HPV, Stool DNA

\section{Text}

In China, the age-standardized 5-year survival rate for patients with all cancers combined is only $30.9 \%$ [1], which is much lower than that in the United States (68\%) [2] and that in the United Kingdom (54.3\%) [3]. There are three main reasons for the huge discrepancies of cancer treatment outcomes between China and developed countries: (1) differences in the spectrum of cancer types; (2) differences in early detection rates; and (3) differences in the percentage of cancer patients receiving standardized treatment.

\section{Spectrum of cancer types}

In the US and other western countries, gastric, liver, and esophageal cancers are less common, whereas in China, these malignancies are consistently among the top 10

\footnotetext{
*Correspondence: qianchn@sysucc.org.cn

Department of Nasopharyngeal Carcinoma, State Key Laboratory of Oncology in South China, Collaborative Innovation Center for Cancer Medicine, Sun Yat-sen University Cancer Center, Guangzhou 510060, Guangdong, P. R. China
}

most common cancer types [4-6]. Patients with these three types of cancer usually have shorter survival in contrast to patients with prostate and breast cancers, the latter two being more common in the US and other western countries [7]. The differences in the spectrum of cancer types can hardly be changed within a decade. However, along with gradual changes in the Chinese lifestyle, as well as the application of vaccinations against hepatitis B and $\mathrm{C}$ virus infections, the incidence of gastric, esophageal, and liver cancers are expected to decline in the next two decades.

\section{Early detection rates and at-home cancer screening} Patient survival for many malignancies is mainly dependent on the stage of the disease. The most important reason underlying the discrepancies of the curative rates between China and developed countries is that early cancer detection rates are pretty low for most of the cancer types in China. For operable gastric cancers in China, stage I diseases only account for $18 \%$, and approximately $59 \%$ are stage III-IV diseases [8]. Contrastingly, in Japan, early detection rates are very high, with over $60 \%$ of stage 
I diseases and $24 \%$ of stage III-IV diseases [9]. For breast cancer, stage I diseases account for only $13.5 \%$ of all cases in China, in contrast, it is $50.5 \%$ in the US [10]. For colorectal cancer, early detection rates in large city hospitals in China is $30 \%$ [11], whereas the average in the US is $38.5 \%$ [12]. Clearly, more endeavors need to be made to significantly increase the early detection rates of major cancers in China.

The application of cancer screening for major cancers in healthy populations using current medical technologies is impeded by two main difficulties. The first difficulty is the expensive cost of current technologies. Due to limited financial resources, the state-owned medical insurance agencies for most Chinese people cannot cover the annual workup for major cancers using traditional technologies, e.g., chest X-ray for lung cancer, let alone using more accurate yet expensive technologies, e.g., low-dose computed tomography scanning for lung cancer. Another difficulty is the limited number of healthcare practitioners in China to complete population-based screening for major cancers using traditional technologies, which are highly dependent on professionals for operation [8].

Some novel and inexpensive technologies need to be invented to simultaneously overcome these two difficulties in China and other developing countries facing similar challenges. Encouragingly, several promising techniques for at-home cancer screening have been approved for clinical practice in the US. By detecting tumor specific KRAS mutations, abnormal NDRG4, and bone morphogenetic protein 3 (BMP3) methylation, plus hemoglobin immunoassays of stool samples, a company named Exact Sciences has developed an at-home screening kit for detecting colorectal cancer, as well as advanced precancerous lesions, with satisfying sensitivity and specificity [13]. For cervical cancer screening, technologies based on self-collected vaginal samples for human papillomavirus infection (HPV) testing are available and currently under clinical validation $[14,15]$. More promisingly, highly sensitive nanoarray sensors for exhaled volatile organic compounds have recently been developed for early detection of lung cancer using breath samples, which can even detect epidermal growth factor receptor $(E G F R)$ mutation for differential diagnosis [16, 17].

Before widespread use of at-home screening technologies in China, validation trials need to be conducted to optimize the techniques and to customize the analytical criteria for the Chinese population. These endeavors could be made by establishing several institutions in different parts of the country responsible for conducting clinical trials, optimizing screening systems, and routinely testing and storing the samples.

\section{Standardized treatment}

It is estimated that over $60 \%$ of cancer patients in China are not treated in specialized cancer hospitals or cancer centers but treated in general hospitals. Radiotherapy in some general hospitals is limited and/or inaccessible, therefore, a significant portion of cancer patients do not receive standard treatment following international guidelines. Another challenge is the shortage of oncological specialists in China. China has launched nationwide residency training programs in 2014, including a radiation oncologist residency training program. However, the long time-discussed specialist training programs for medical oncologists and surgical oncologists have not yet been launched. It is expected that by improving the education and training systems for oncological specialists in China, more and more patients will be treated in accordance with international guidelines.

In conclusion, many efforts need to be made to improve the survival rates of cancer patients in China. The most important one is to improve early detection rates of major cancers in China using novel and affordable technologies allowing at-home sample collection by the patients themselves. All of these efforts could be helpful in setting up a successful example for other developing countries with limited medical resources and a limited number of healthcare practitioners.

\section{Acknowledgements \\ This work was supported by grants from the National Natural Science Foundation of China (No. 81472386, No. 81672872), the National High Technology Research and Development Program of China (863 Program) (No. 2012AA02A501), the Science and Technology Planning Project of Guang- dong Province, China (No. 2014B020212017, No. 2014 B050504004 and No. 2015B050501005), and the Provincial Natural Science Foundation of Guang- dong, China (No. 2016A030311011).}

\section{Competing interests}

The author declares that he has no competing interests.

Received: 13 August 2017 Accepted: 17 August 2017

Published online: 21 August 2017

\section{References}

1. Zeng H, Zheng R, Guo Y, Zhang S, Zou X, Wang N, et al. Cancer survival in China, 2003-2005: a population-based study. Int J Cancer. 2015;136:1921-30. doi:10.1002/ijc.29227.

2. National Institutes of Health. Yesterday, Today, Tomorrow: $\mathrm{NIH}$ research timelines. 2013. https://report.nih.gov/NIHfactsheets/ViewFactSheet. asp $x$ ? csid $=75 \& k e y=$ C\#C.

3. Cancer Research UK. Cancer survival statistics for all cancers combined. 2014. http://www.cancerresearchuk.org/health-professional/ cancer-statistics/survival/all-cancers-combined\#heading-Zero.

4. Chen W, Zheng R, Zeng H, Zhang S. The updated incidences and mortalities of major cancers in China, 2011. Chin J Cancer. 2015;34:502-7. doi:10.1186/s40880-015-0042-6.

5. Chen W, Zheng R, Zeng H, Zhang S. The incidence and mortality of major cancers in China, 2012. Chin J Cancer. 2016;35:73. doi:10.1186/ s40880-016-0137-8. 
6. Zheng R, Zeng H, Zhang S, Chen W. Estimates of cancer incidence and mortality in China, 2013. Chin J Cancer. 2017;36:66. doi:10.1186/ s40880-017-0234-3.

7. Allemani C, Weir HK, Carreira H, Harewood R, Spika D, Wang XS, et al. Global surveillance of cancer survival 1995-2009: analysis of individual data for 25,676,887 patients from 279 population-based registries in 67 countries (CONCORD-2). Lancet. 2015;385:977-1010. doi:10.1016/ S0140-6736(14)62038-9.

8. Wang Y, Wei S, Li Y, Deng S, Luo Q, Li Y. Challenges and a response strategy for the development of nursing in China: a descriptive and quantitative analysis. J Evid Based Med. 2013:6:21-33. doi:10.1111/jebm.12016.

9. Fujiwara Y, Fukuda S, Tsujie M, Ishikawa H, Kitani K, Inoue K, et al. Effects of age on survival and morbidity in gastric cancer patients undergoing gastrectomy. World J Gastrointest Oncol. 2017;9:257-62. doi:10.4251/ wjgo.v9.i6.257.

10. Chen C, Sun S, Yuan JP, Wang YH, Cao TZ, Zheng HM, et al. Characteristics of breast cancer in Central China, literature review and comparison with USA. Breast. 2016:30:208-13. doi:10.1016/j.breast.2016.01.004.

11. Fang YJ, Wu XJ, Zhao Q, Li LR, Lu ZH, Ding PR, et al. Hospital-based colorectal cancer survival trend of different tumor locations from 1960s to 2000s. PLoS ONE. 2013;8:e73528. doi:10.1371/journal.pone.0073528.

12. May FP, Glenn BA, Crespi CM, Ponce N, Spiegel BMR, Bastani R. Decreasing black-white disparities in colorectal cancer incidence and stage at presentation in the United States. Cancer Epidemiol Biomark Prev Publ Am Assoc Cancer Res Cosponsored Am Soc Prev Oncol. 2017;26:762-8. doi:10.1158/1055-9965.EPI-16-0834

13. Imperiale TF, Ransohoff DF, Itzkowitz SH, Levin TR, Lavin P, Lidgard GP, et al. Multitarget stool DNA testing for colorectal-cancer screening. N Engl J Med. 2014;370:1287-97. doi:10.1056/NEJMoa1311194.

14. Chen K, Ouyang Y, Hillemanns $P$, Jentschke M. Excellent analytical and clinical performance of a dry self-sampling device for human papillomavirus detection in an urban Chinese referral population. J Obstet Gynaecol Res. 2016;42:1839-45. doi:10.1111/jog.13132.

15. Zhao FH, Lewkowitz AK, Chen F, Lin MJ, Hu SY, Zhang X, et al. Pooled analysis of a self-sampling HPV DNA Test as a cervical cancer primary screening method. J Natl Cancer Inst. 2012;104:178-88. doi:10.1093/jnci/ djr532.

16. Lopez-Sanchez LM, Jurado-Gamez B, Feu-Collado N, Valverde A, Canas A, Fernandez-Rueda JL, et al. Exhaled breath condensate biomarkers for the early diagnosis of lung cancer using proteomics. Am J Physiol Lung Cell Mol Physiol. 2017: doi:10.1152/ajplung.00119.2017.

17. Shlomi D, Abud M, Liran O, Bar J, Gai-Mor N, llouze M, et al. Detection of lung cancer and EGFR mutation by electronic nose system. J Thorac Oncol Off Publ Int Assoc Study Lung Cancer. 2017;. doi:10.1016/j. jtho.2017.06.073.

\section{Submit your next manuscript to BioMed Central and we will help you at every step:}

- We accept pre-submission inquiries

- Our selector tool helps you to find the most relevant journal

- We provide round the clock customer support

- Convenient online submission

- Thorough peer review

- Inclusion in PubMed and all major indexing services

- Maximum visibility for your research

Submit your manuscript at www.biomedcentral com/submit 